\title{
The Presentation of Methodology about Build a Manual and System for Restoration Works in an Emergency
}

\author{
Jong in Choi $^{2}$, Hyun dong Lee ${ }^{1,2}$ and Pill Jae Kwak ${ }^{1}$ \\ 1 Korea Institue of Civil Engineering and Building Technology, Environment \\ Research Department. Daehwa-dong, Ilsanseo-gu, Goyang-si, Gyeonggi-do, Republic \\ of Korea \\ 2 Korea University of Science and Technology, Construbtion and Environment \\ Engineering. 217, Gajeong-ro, Yuseong-gu, Daejeon, Republic of Korea \\ mynameis764@google.com
}

\begin{abstract}
Recently, some unexpected disasters have been occurring and there are much more damages from unexpected disasters than expected. The reason is that there is no way to make an accurate estimate about damages from unexpected disaster. So, it is efficient way to make a plan to do a restoration work promptly. For this purpose, we have been doing research to develop a restoration manual and data-base system prepared for emergency situations. However, the study is not finished yet. There remain some related research processes to make the results more in-depth.
\end{abstract}

Keywords: Waterworks, water pipe networks, restoration work, unexpected disaster

\section{Introduction}

Recently, some damages of infrastructure are increasing. These situations are mostly caused by carelessness of workers or abnormal climate exchange such as earthquake, heavy snow. It could be classified into natural disaster and man-made disaster. It is possible to reduce the amount of damage through the construction activities and systematic maintenance management. But if unexpected disasters which are more powerful than ever occur, the damage will become worse and cause significant loss in various aspects. So restoration works could be more important in the event of unexpected disasters. It is essential to developing inspection standard of facilities and emergency restoration system for the above-mentioned emergency situations [4].

The paper proposes efficient restoration manuals which suit the necessary occasions for emergency situations and application plans of result data for emergency situation that would happen later.

There were some steps for the study. The first step is to collect data which are necessary. Several meetings were held with several local governments and we could get some data about diagnose work of water pipe network. After collecting materials, the study proceeded to gather some result data for classification into two groups, the physical and chemical features and examine some data of advanced countries in waterworks field. After that, the study about national application plan was carried out.

The second step is to make an investigation for some equipment which is necessary for the restoration work. But some equipment for restoration is not standardized among different companies and regions. So the paper just introduces the equipment and explains about their function briefly. 
The third step is to consult with specialists about the manual and application plans. This step is for making developed manual and plan more credible. These types of the manual and application plans did not exist. Furthermore, it is very difficult to prove the practicality because the scale of tests is quite extensive. So consulting with specialists about development results and establishing improvement plan are more efficient.

Through this process, the manual for restoration work and application plans are developed. But the study is not finished. The study is still very much a work in progress. Therefore, it is expected that we could got better results.

\section{Collection \& Analysis of Materials}

There are several reasons for collection \& analysis of materials. Most of all, through collecting materials, it was possible to decide how to make the manual and application plan.

Table 1 is about the basic information of some kinds of pipes which have been used in Korea. In the Table, there is KS. KS is Korean Industrial Standards about all kinds of products made in Korea. It is possible to find out some information by reading KS. Through the Table, it is possible to know the pipe use state.

Table 1. Some Kinds of Pipes used in Korea

\begin{tabular}{|c|c|c|}
\hline $\mathbf{K S}$ & Pipe & Characteristic \\
\hline D 3537 & $\begin{array}{c}\text { Galvanized } \\
\text { steel pipe }\end{array}$ & $\begin{array}{l}\text { Carbon steel pipe for pipelines are } \\
\text { plated by zinc, use hydrostatic is under } \\
\text { the } 100 \mathrm{~mm} \text { and it uses mainly water } \\
\text { pipe for water supply }\end{array}$ \\
\hline D 3623 & $\begin{array}{l}\text { Corrosion } \\
\text { resistance } \\
\text { steel pipe }\end{array}$ & $\begin{array}{l}\text { Generally, it uses a waterworks pipe } \\
\text { coated white by corrosion resistance } \\
\text { welded steel in water supply }\end{array}$ \\
\hline D 3565 & $\begin{array}{l}\text { Wrapped steel } \\
\text { pipe }\end{array}$ & $\begin{array}{l}\text { Generally, it uses a steel pipe using } \\
\text { hydrostatic under the } 100 \mathrm{~mm} \\
\text { waterworks piping }\end{array}$ \\
\hline D 3608 & $\begin{array}{l}\text { Steel pipe coated } \\
\text { by an epoxy resin }\end{array}$ & $\begin{array}{l}\text { It is steel pipe coated epoxy resin that } \\
\text { used maximum use pressure under } \\
1.0 \mathrm{Mpa} \text { in waterworks }\end{array}$ \\
\hline D 3619 & $\begin{array}{c}\text { Polyethylene } \\
\text { lining Steel pipe }\end{array}$ & - \\
\hline
\end{tabular}

Figure 1. is graphs about repetition rate and quantity of leakage in certain cities. The graphs are made by referring the statistics of waterworks (2013). In the graphs, there are two cities. It is just part of the materials. Other than that, statistics are organized by regional groups.

Thorough these materials, it is possible to know about how much quantity of water have been leaking monthly. And, when disasters occur, the more accurate decision could be possible by finding damaged area, considering the quantity of leakage by referring these materials. 
Thorough these materials, it is possible to know about how much quantity of water have been leaking monthly. And, when disasters occur, the more accurate decision could be possible by finding damaged area, considering the quantity of leakage by referring these materials.
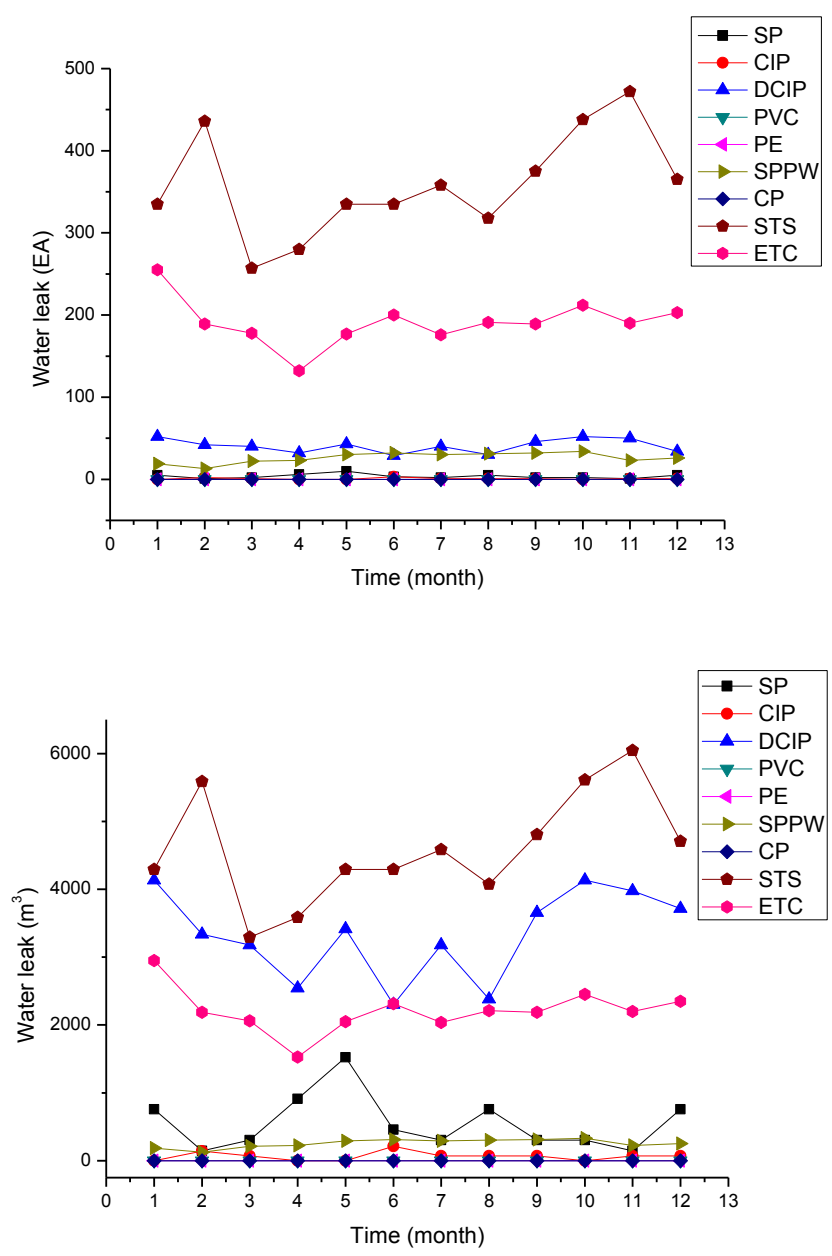

\section{Figure 1. Some Graphs about Repetition Rate and Quantity of Leakage in Certain Cities}

Figure 2 is a part of excel files made by using gathered data from local government in Korea. Periodically, local governments conduct research for the pipe deterioration in water distribution networks. It is carried by referring to the manual of Waterworks Pipeline Network Diagnosis. This manual introduces several standards divided into chemical and physical composition for prediction about deterioration of water pipes (The ministry of environment, 2007). However, the research is not encouraged for local governments to do at certain times. So, the local governments have been conducting research when they judge the time to do research about water pipes. Furthermore, there are not standardized paper forms so each government decides the time to do research autonomously and paper forms. For these reasons, it is not easy to gather materials. 


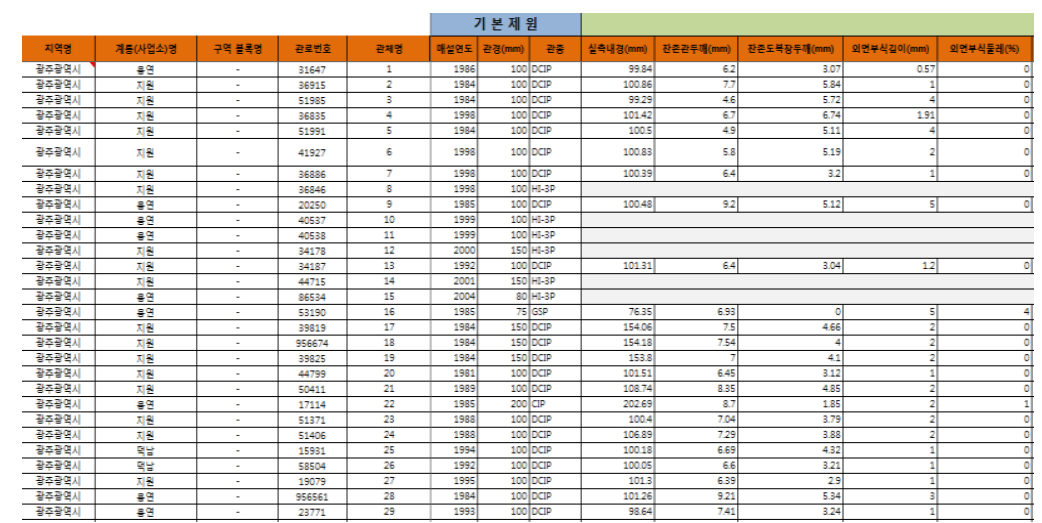

Figure 2. An Excel File Made by Using Gathered Data from Local Government All Local Governments Do Research for Waterworks after Research they Make a Report for Maintenance Work

These files are also classified into chemical formation and physical formation. And each formation is composed of several items such as a type of pipe, thickness and so on. By referring to the standards in the manual of Waterworks Pipeline Network Diagnosis, it could be possible to predict a scale of pipes damaged by disaster and distribution status by types of pipes.

Through the process of the collection and analysis of materials, the background information could settle into shape. However, it is not perfect because there is not a lot of information about the unexpected disaster. Therefore, the continuous research about water pipes buried is essential to make the manual and Data-Base system more reliable and concrete.

\section{Rapid Restoration Manual for Water Pipe Networks}

Rapid restoration manual for water pipe networks is an official name of the aforementioned restoration manual. This is a guideline for restoration of metallic pipes based on the result of collection \& analysis of materials. The manual is made to cope with various occasions such as typhoon, earthquake and so on and suggest prompt decision plans to minimize damages.

In case of some other countries, they use pipes of plastic materials such as PVC, PE and so on. However, through the previous research process, it is identified that the great part of water pipe used in Korea is steel pipe. Steel pipes are not easily breakable but it is more expensive, less flexible and durable than plastic pipes. So, it could incur expenses for maintenance. Plus, if the steel pipe is damaged, the restoration work need so many times because there are various processes to find an accident spot, estimate the exact amount of replacement goods. 


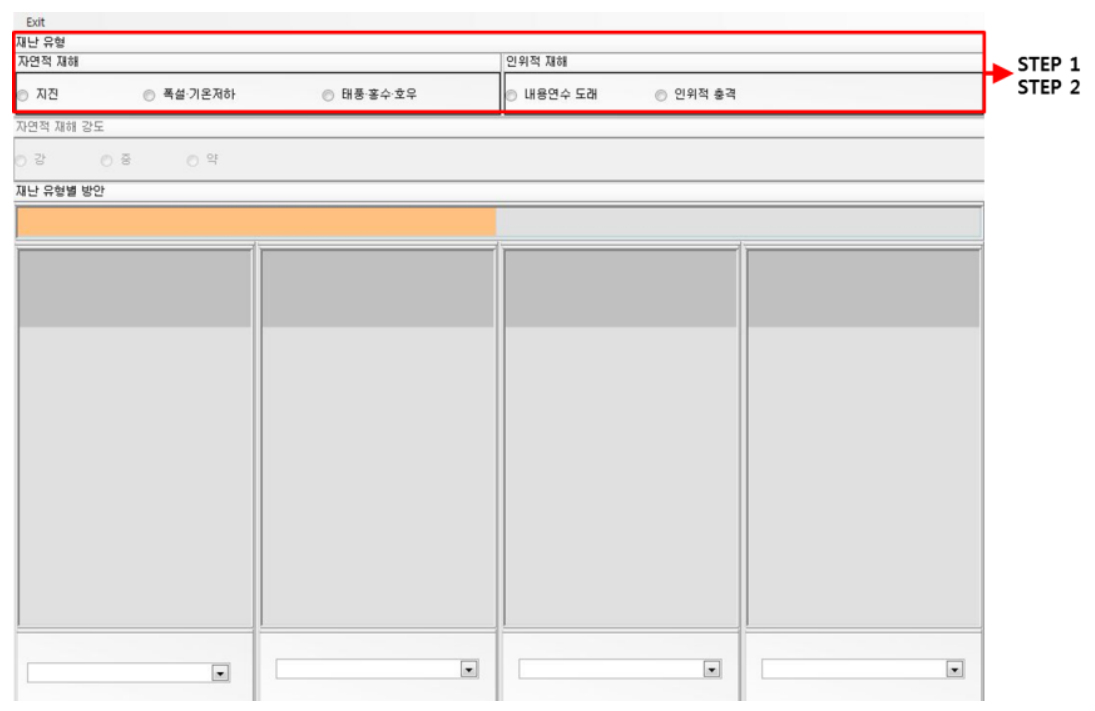

\section{Figure 3. The Rapid Restoration Manual for Water Pipe Networks in the Step 1, 2}

To take into account various situations, it is divided into three steps. The first step is a broad classification of disaster into natural disaster or man-made disaster. Through this step, it is possible to speculate the scale of damage roughly.

The second step is item selection of the broad classification. In case of natural disaster, there are several items such as typhoon, earthquake and heavy snow. And man-made disaster has two items, accidents by carelessness of workers and deterioration of water networks. It is necessary to go through this step because restoration work schedules could be different in types of disaster.

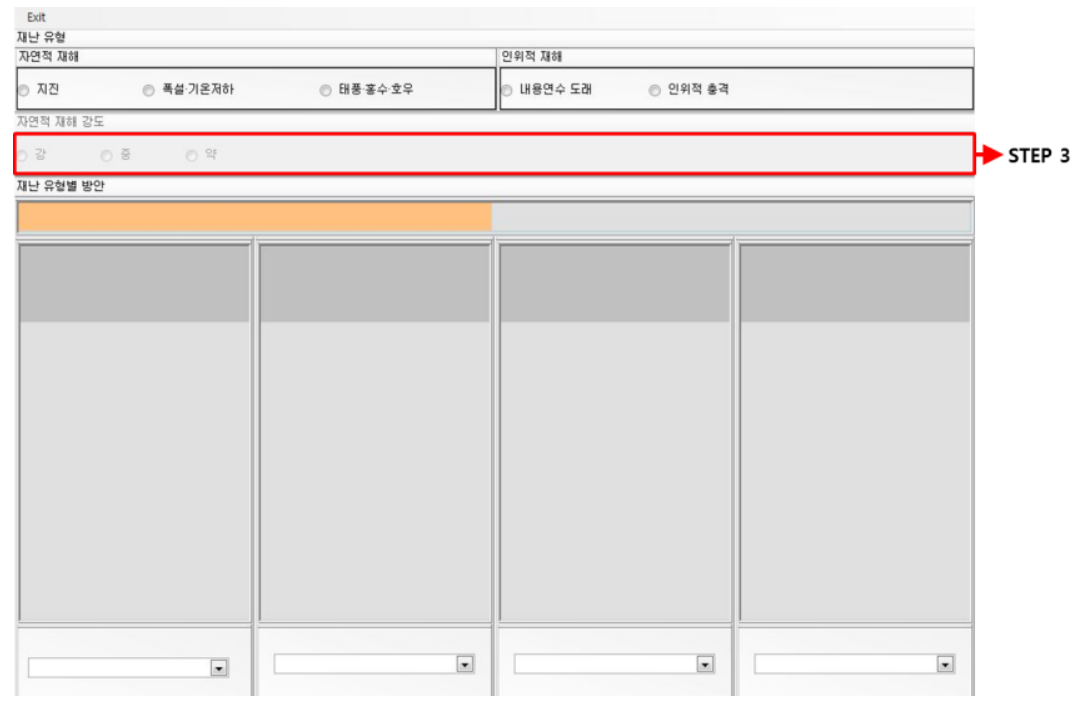

Figure 4. The Rapid Restoration Manual for Water Pipe Networks in the Step 3

Finally, the third step is strength selection of the selected item. It could be different in the strength of disaster. So, preparatory work for restoration should be conducted after strength 
selection. In this study, the strength of disaster is divided into 3 levels. But if it is impossible to divide into 3 levels, using 2 levels could be suitable. Figure 2 is rapid restoration manual programed effectively.

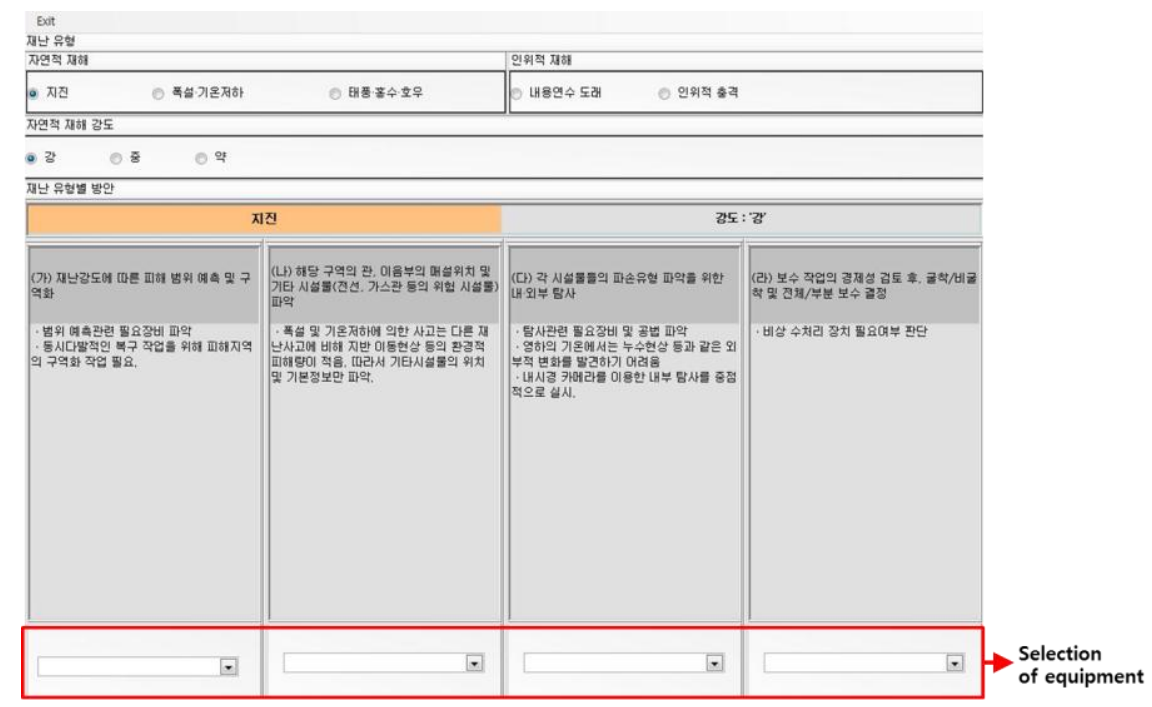

\section{Figure 5. The Rapid Restoration Manual for Water Pipe Networks in Additional Step for Selection of the Proper Equipment}

Additionally, some equipment is introduced for more prompt decision of restoration works. But it is just suggestion because there could be many kinds of equipment for restoration work. They have both merits and demerits. Also, it could be different from equipment which needs for the restoration work in some cases. That is why the paper just introduces some equipment regarded as necessary equipment for restoration works.

\section{Data-Base System of Restoration Work Results}

The object of developing Data-Base system is to maximize the information from last restoration works. When unexpected disasters occur, the restoration work will be slower than usual and the amount of damage will become worse. So to deal with this problem effectively, it is necessary to build Data-Base system to make the best use of background information obtained in the past.

To build Data-Base system for restoration works, we sought some advice from experts and could get some information about what information we should collect to minimize the damage of next unexpected disaster. It was hard to build the Data-Base system because there was not much information for restoration works and some information were not organized systematically.

The Data-Base system was developed to utilize reference materials. This Data-Base system has some contents about many kind situations of restoration works. So it could be possible to search related work results in case of necessity. 


\begin{tabular}{|c|c|c|}
\hline Tyре & Index & Result \\
\hline \multirow{10}{*}{ Earthquake } & Scale of disaster & degrees \\
\hline & Type of the pipe & \\
\hline & Possibility of aftershock & $(\mathrm{O} / \mathrm{X})$ \\
\hline & Total length of damaged pipes & m \\
\hline & Replacement ratio(replacement/damaged) & $\%$ \\
\hline & Other buried facilities & $(\mathrm{O} / \mathrm{X})$ \\
\hline & Drawing of the damaged district & $(\mathrm{O} / \mathrm{X})$ \\
\hline & Survey equipment for internal pipes & set \\
\hline & Excavators & set \\
\hline & Number of Available manpower & \\
\hline
\end{tabular}

\section{Figure 6. The Input Format for the Information about Restoration Work Results}

The Figure 6 is some parts of the Data-Base system to input data about restoration work results. It is also divided into some steps for effective utilization which makes workers take many kind situations into account such as natural disaster, man-made disaster.

The first step is selection of disaster type. This process makes users more easily find the information they want to get. The second step is a search for the information of similar situations. The way for search is encouraged to be based on the information that it is possible to know about what workers could collect at the present situation.

The last step is inputting some result data. The object of this step is for workers to provide information about related background of restoration works. Through this step, it is possible to accumulate information and organize the resource systematically. After commercialization of the Data-Base system, the more information is accumulated, the more specific solutions could be provided. This process could be made by using algorithm.

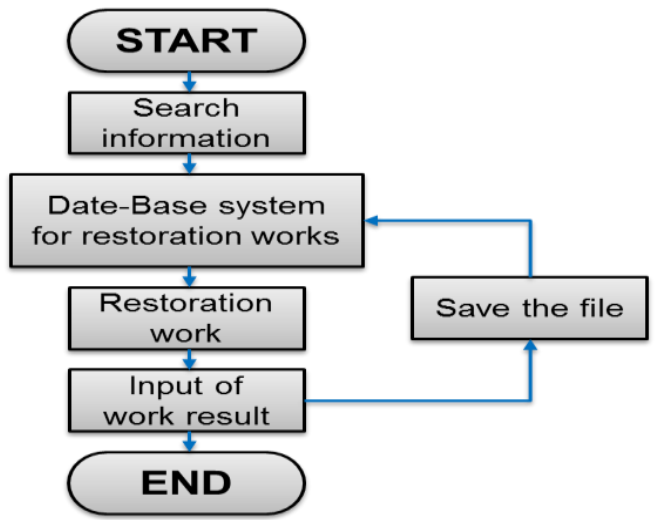

\section{Figure 7. The Algorithm about Operation Process of the Data-Base System}

This algorithm is about the operation process of the Data-Base system. Based on this algorithm, the program for Data-Base system would be developed. In this algorithm, the important step is Data-Base system for restoration works and input of work result. These two steps are operated complementarily; thereby various information could be accumulated systematically. 


\section{Conclusion}

The results of this paper are not made perfectly. There remains some related research process. These manual program and Data-Base system need maintenance control consistently. Additionally for making the best use of these manual and system, it is necessary for each government to use it. Because by using it commonly, regional information could be shared effectively. If they share information about restoration works each other, much more information could be used as reference materials.

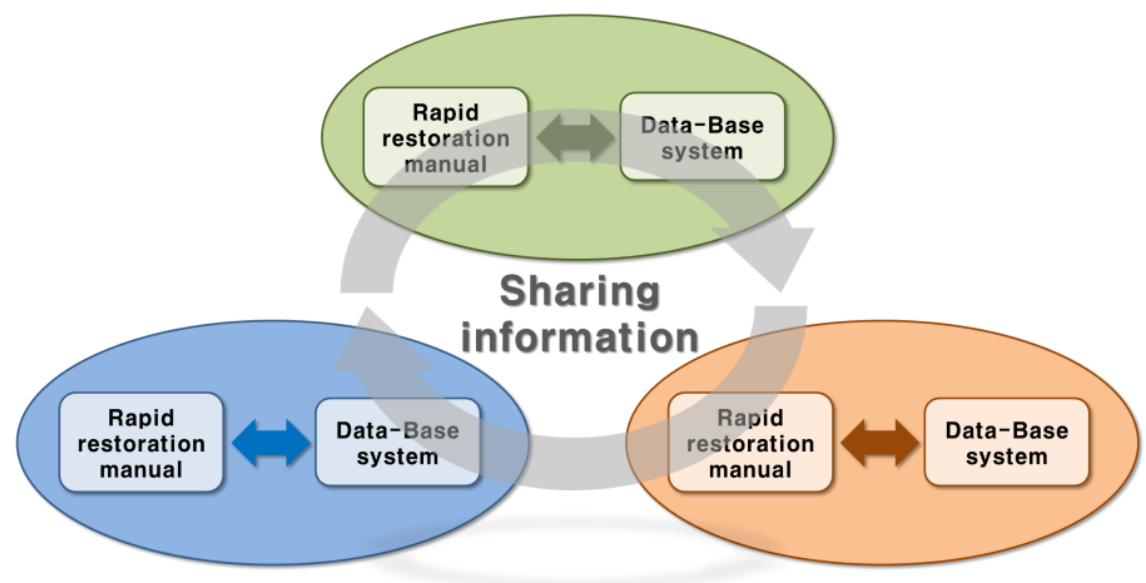

\section{Figure 8. The Sharing Information by Regional Groups}

However, to make these manual and program perfectly, it is required to do field test additionally for reliability development of the manual program and data-base system because these are used in the urgent situations. So, the field tests considering real-life situation and feedback should be required. Although it is hard to conduct a research under conditions that closely resemble real situations, the field test considering various situations should be conducted.

\section{Acknowledgements}

This research was supported by a grant from the nation research, GBEST (Global Business oriented Energy efficient smartly managed Technology innovated)

This paper is a revised and expanded version of a paper entitled "The field analysis of restoration on water network for emergency" presented at NGCIT2014, Hochiminh (Vietnam), 24-26, Oct., 2014.

\section{References}

[1] "Ministry of Environment”, Manual of Waterworks Pipeline Network Diagnosis, (2007).

[2] "Gwang-Ju City", Report about waterworks system plan in Gwang-Ju, (2013).

[3] "Waterworks Headquaters Daegu Metropolitan city", Report about waterworks system plan in Gwang-Ju, (2014).

[4] J. I. Choi, P. J. Kwak, S. W. Kang, J. H. Lee and H. D. Lee, "The restoration manual on water network for emergency", P-26, Korean Society of Water and Wastewater \& Korean Society on Water Environment, (2014).

[5] "Ministry of Environment", Statics of Waterworks, (2012).

[6] “Gwangju metropolitan city”, technical diagnostic report, (2013), pp. 59-153.

[7] "Daegu metropolitan city", technical diagnostic report, (2014), pp. 1-32. 
[8] "Busan metropolitan city", technical diagnostic report, (2010), pp. 168-296.

[9] "Bucheon city", technical diagnostic report, pp. 110-122.

[10] "Ulsan metropolitan city", technical diagnostic report, (2010), pp. 1-1 - 8-70.

\section{Authors}

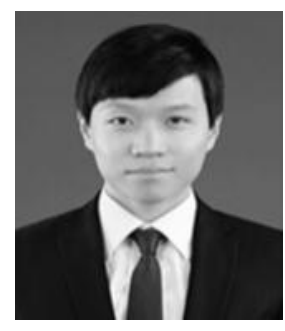

\section{Jong In, Choi}

ACADEMIC BACKGROUND:

Aug 2013, Hanyang University

$\mathrm{BD}$ in Civil and Environmental Engineering

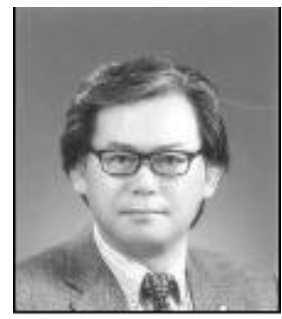

\section{Hyun dong Lee}

ACADEMIC BACKGROUND:

Oct 1993, Kyoto University, Post-Ph.D in Environmental Engineering

Aug 1991, Hanyang University

$\mathrm{Ph}$. D in Civil and Environmental Engineering

Feb 1987, Hanyang University

MS in Civil and Environmental Engineering

PROFESSIONAL EXPERIENCE:

Sep 2007 , Korea University of Science \& Technology, Professor with Department of Construction \& Environment Engineering

Dec 2004 Dec 2005, the University of Iowa, Visiting Professor with Department of Civil \& Environmental Engineering

Jul 1987 , Korea Institute of Civil Engineering and Building Technology, Senior Research Fellow, Environmental Engineering Research Department 
International Journal of Control and Automation Vol. 7, No. 12 (2014) 